\title{
Licenciatura em Computação: Desafios e Oportunidades na Perspectiva do Estudante
}

\author{
Wilk Oliveira dos Santos ${ }^{1}$, Célia Cristina Vilela da Silva ${ }^{2}$, Lucas Tadeu Hinterholz ${ }^{3}$ \\ ${ }^{1}$ Núcleo de Excelência em Tecnologias Sociais (NEES) - Instituto de Computação (IC) - \\ Universidade Federal de Alagoas (UFAL) - Maceió - AL - Brasil \\ ${ }^{2}$ Curso de Licenciatura em Computação - Universidade de Pernambuco (UPE) - \\ Garanhuns - PE - Brasil \\ ${ }^{3}$ Departamento de Computação - Curso de Licenciatura em Computação - \\ Universidade de Santa Cruz do Sul (UNISC) - Santa Cruz do Sul - RS - Brasil \\ wos@ic.ufal.br, \{celinhacristina20, lhinterholz\}@gmail.com
}

\begin{abstract}
Resumo. A Informática na Educação encontra-se em uma situação paradoxal, trazendo a tona uma série de desafios no âmbito do uso das novas tecnologias digitais na educação, bem como do próprio ensino da Computação enquanto ciência. No intuito de formar um profissional capaz de lidar com estas situações, foi criado o curso de Licenciatura em Computação que tem se expandido e trazido à tona uma série discussões. Este artigo apresenta estudo que tem por objetivo identificar e discutir desafios e oportunidades do curso na perspectiva do estudante. Os indicadores apontam para três desafios $e$ oportunidades principais: (i) articulação entre teoria e prática na perspectiva da formação docente, (ii) estruturação e organização dos estágios supervisionados e (iii) promoção e abrangência das oportunidades ao egresso.
\end{abstract}

\begin{abstract}
The Computers in Education is in a paradoxical situation, highlighting a series of challenges in the field of the use of new digital technologies in education, as well the teaching of Computers Science. In order to form professionals capable of dealing with these situations, the Computer Science Degree course was created in Brazil. Over the past few years, the course has been expanded to bring forth a series discussed. Thus, this paper aims to identify and discuss challenges and opportunities of course from a student perspective. The results point to three main challenges and opportunities: ( $i$ ) articulation between theory and practice in the perspective of teacher education, (ii) structuring and organization of supervised internships (stages), and (iii) promotion and comprehensiveness of opportunities for the egress.
\end{abstract}

\section{Introdução}

Existe uma incongruência quando se trata de Informática na Escola no Brasil. Se por um lado compreende-se a importância das tecnologias no ensino, por outro, existe 
resistência à sua inclusão devida, em parte, ao despreparo para utilizá-las. Contudo, a própria Lei de Diretrizes e Bases do Ensino Nacional (LDB 9496/1996) institui a Informática como um elemento complementar de estudo e apoio interdisciplinar na escola, mesmo que não seja obrigatória no currículo formal. A partir desse respaldo legal, pode-se afirmar ser uma questão de tempo para as escolas adequarem-se e buscarem professores desta área.

Papert (1985), já destacava que todo aluno deveria ter um computador em sala de aula para aprender, no que denominou construcionismo. Ainda que de forma tímida, as políticas públicas começam a se alinhar a esta convicção do autor, que vem desde a década de 1960. Concordando com a LDB, o Plano Nacional de Educação - PNE (20142024) reforça a necessidade de informatização da escola quando propõe a ampliação do número de laboratórios de Informática (Estratégia 6.2), oportunizando a ascensão de um novo tipo de profissional.

Nesse contexto, surge o Licenciado em Computação, profissional formado por curso de graduação denominado Licenciatura em Computação. Segundo Matos e Silva (2012), este profissional está habilitado para atuar de forma integradora na Educação Básica em todos os seus níveis de ensino. Isso diz respeito, tanto ao uso e desenvolvimento de novas tecnologias para educação, quanto ao próprio ensino de Computação enquanto ciência.

O curso de Licenciatura em Computação teve sua primeira oferta na Universidade de Brasília, em 1997. A segunda oferta data de 1999, na Universidade de Santa Cruz do Sul e, a partir de 2012, houve grande expansão; segundo o Ministério de Educação e Cultura - MEC, já são mais de 150 cursos no Brasil no ano de 2017. Nesse sentido, Cruz et. al (2016) fazem uma análise da Licenciatura em Computação e consideram este, um curso de formação profissional completa. Segundo o estudo de Cruz, o currículo integra as áreas de Computação com a Educação, Matemática, Psicologia, Sociologia, Filosofia, Línguas Portuguesa e Inglesa, e forma um professor multidisciplinar.

Apesar disso, a carreira do Licenciado Computação ainda não está plenamente construída. Isto se deve aos poucos espaços legalmente constituídos para o profissional no contexto da Educação Básica. Segundo Castro e Vilarim (2013), a Licenciatura em Computação também enfrenta dificuldades em relação à sua identidade - o que faz? $\mathrm{O}$ que ensina? - bem como a adequação pedagógica dentro das escolas; questões de mercado e reconhecimento da profissão também dificultam a expansão da atividade, demandando a identificação de desafios e oportunidades que possam nortear o planejamento do curso para os próximos anos.

Nesse sentido, este artigo apresenta uma série de desafios e oportunidades ao curso de Licenciatura em Computação, obtido por meio de uma pesquisa empírica realizada online, destinada a estudantes e egressos dos cursos de Licenciatura em Computação do Brasil. Os dados obtidos expressam as expectativas e anseios em relação à formação e ao mercado de trabalho do Licenciado em Computação. O artigo está organizado da seguinte forma: a segunda seção contempla a revisão literária do trabalho; a terceira seção descreve a metodologia de trabalho aplicada à pesquisa e quantificação dos dados; a seção quatro descreve os resultados gerais da pesquisa, 
VI Congresso Brasileiro de Informática na Educação (CBIE 2017)

Anais do XXIII Workshop de Informática na Escola (WIE 2017)

enquanto a seção cinco relata os resultados da pesquisa nas dimensões de desafios e oportunidades. Por fim, a sexta seção descreve as limitações do estudo e, a sétima, apresenta as considerações finais.

\section{Revisão da Literatura}

Esta seção tem por objetivo contemplar uma revisão dos principais tópicos abordados nesse artigo.

\subsection{Informática na Escola e o Papel da Licenciatura em Computação}

Atualmente, a tecnologia está inserida na sociedade moderna de forma nunca antes vista; para Scaico (2012), isto altera a dinâmica das atividades profissionais, de lazer e até mesmo de estudo. Entretanto, segundo da Silva et al. (2015), tem ocorrido o fato de que a maioria das pessoas são apenas usuárias e não usufruem do artefato de forma que possam promover novos conhecimentos, na contramão do pensamento de Papert (1980): em vez de o computador programar a criança, a criança é que deve programar o computador. Papert também afirma que o computador não deve ser um "professor eletrônico", defendendo a presença de um articulador entre as tecnologias digitais e o ensino de Computação - a ciência - na Educação Básica.

Com o objetivo de formar um profissional que atue nesta mediação, sendo capaz de lidar com o uso e desenvolvimento destas tecnologias na educação e com o próprio ensino da Computação, surgiu o curso de Licenciatura em Computação. O curso é reconhecido pelo Ministério da Educação (MEC) a partir de diferentes denominações, dentre as quais: Licenciatura em Computação, Licenciatura em Ciência da Computação, Licenciatura em Informática, Informática - Licenciatura, Licenciatura Plena em Informática, dentre outras. Estas variações vêm gerando questionamentos e discussões etimológicas acerca da denominação do curso, gerando a necessidade de esclarecermos alguns pontos importantes sobre a nomenclatura adotada nesse trabalho.

Segundo Nunes (2011), existe uma diferença substancial entre Informática e Computação. Para este autor, a Computação corresponde ao processo de resolução de problemas por algoritmos, ou seja, o tratamento de dados onde existe uma entrada, compilação e saída. A Informática, contudo, denota a utilização de tecnologias digitais em determinado contexto como na informatização de uma escola ou empresa, por exemplo. Assim, a Computação está relacionada ao desenvolvimento de solução e, a Informática, a seu uso prático.

Para este trabalho, foi considerado o último relatório Sociedade Brasileira de Computação - SBC que considera como Licenciatura em Computação todos os cursos de "formação de professores para a área de Computação". Com base nesse texto, a utilização predominante do termo "Computação" dá-se pelo interesse em expor o seu caráter científico, quando abordado no contexto da Educação Básica. Baseado nesse ideal é imprescindível que se reconheça a Computação na escola como o ensino e aplicação de teorias relacionadas ao processo de resolução de problemas e não como a mera instrumentalização para utilizar aplicativos.

De acordo com os Referenciais de Formação em Computação - RFC (no 
âmbito da Licenciatura em Computação), os Licenciados em Computação podem atuar em escolas e empresas ou noutras instituições, principalmente, de duas maneiras distintas: i) como professores de Computação, ensinando desde Informática básica até aspectos relacionados ao pensamento/raciocínio computacional, à robótica e ao desenvolvimento de algoritmos e software; ou ii) como agentes integradores $e$ promotores do uso da tecnologia na educação, trabalhando de maneira interdisciplinar na gestão e desenvolvimento de recursos de hardware e software utilizados para ensino $e$ aprendizagem no âmbito da educação presencial ou a distância, dentre outras maneiras substanciais a sociedade atual.

Segundo o mesmo documento, o egresso deve dominar os conhecimentos básicos da Computação a partir dos seus fundamentos matemáticos, no entanto, com a visão de que eles possuem origem e contexto históricos, considerando seus diversos modos de realizabilidade técnica. O Licenciado deve ser capaz de explorar e investigar temas ligados ao pensamento/raciocínio computacional, como abstração, complexidade e mudança evolucionária. O Licenciado em Computação é precipuamente responsável por apresentar a Computação como ciência à escola, e por consequência à sociedade, tendo papel fundamental na construção de narrativas capazes de dar sentido e significado aos conceitos e fenômenos desta ciência.

\section{Metodologia}

O experimento de identificação dos desafios foi conduzido seguindo o modelo de objetivos, questões e métricas (do inglês, Goal Question Metrics (GQM) Wollin et al. 2012). O experimento conduzido nesse estudo é caracterizado como quantitativo, visando identificar e discutir desafios e oportunidades do curso de Licenciatura em Computação no Brasil, na perspectiva do estudante. Seguindo o modelo GQM, foi desenvolvido um questionário contendo 22 questões, divididas em entre 17 questões optativas e cinco dissertativas, alocadas em dois módulos distintos: (i) dados demográficos e (ii) percepções do curso.

Inicialmente foi executado um estudo piloto, contando com a participação de cinco estudantes de Licenciatura em Computação de uma universidade pública do estado de Pernambuco, que responderam e avaliaram o questionário. Após a obtenção das respostas, o mesmo questionário foi ainda avaliado por sete professores de Licenciatura em Computação de três diferentes instituições nacionais, com o objetivo de identificar se o propósito principal do questionário estava sendo atingido. As respostas foram analisadas para geração da versão final do questionário (disponibilizado no link do primeiro item de rodapé deste artigo). A versão final foi divulgada amplamente nas principais listas relacionadas entre os meses de Janeiro e Maio de 2017.

\section{Resultados Gerais}

Foram obtidas 190 respostas válidas ${ }^{1}$, sendo $140(73,7 \%)$ de estudantes do sexo masculino, $49(25,8 \%)$ estudantes do sexo feminino e um $(0,5 \%)$ que preferiu não informar, confirmando os resultados do último relatório da $\mathrm{SBC}$, que segundo Nunes (2015) mostra que maioria das matrículas, não somente da Licenciatura em

\footnotetext{
${ }^{1}$ Questionário e quantificação dos dados: http://migre.me/wI891
} 
VI Congresso Brasileiro de Informática na Educação (CBIE 2017)

Anais do XXIII Workshop de Informática na Escola (WIE 2017)

Computação, mas de todos os cursos da área de Computação, tem sido de estudantes do sexo masculino. Em relação à idade destes estudantes, apenas seis $(3,2 \%)$ têm idade inferior a 18 anos, $80(42,1 \%)$ têm idade entre 18 e 24 anos, $70(36,8 \%)$ têm idade entre 26 e 35 anos e $34(17,9 \%)$ idade superior a 36 anos.

As respostas obtidas foram de estudantes de 14 diferentes estados Brasileiros, sendo a maioria dos estados de Pernambuco e da Bahia $(23,7 \%$ e $17,9 \%$ respectivamente). Esta adesão de representantes de todas as regiões indica forte representação nacional do curso de Licenciatura em Computação, segundo Prietch e Pazeto (2010) destacando a perspectiva de crescimento do curso em diferentes regiões do país apontado desde o ano de 2010 e consolidado nos últimos relatórios da SBC apresentado por Nunes (2015). A Figura 1 destaca a perspectiva de crescimento do curso, desde o ano de 1997 a 2015 de acordo com cada região. O questionário final disponibilizado, bem como os dados gerais advindos das respostas recebidas, está disponibilizado por meio do link contido no primeiro item de rodapé deste artigo.

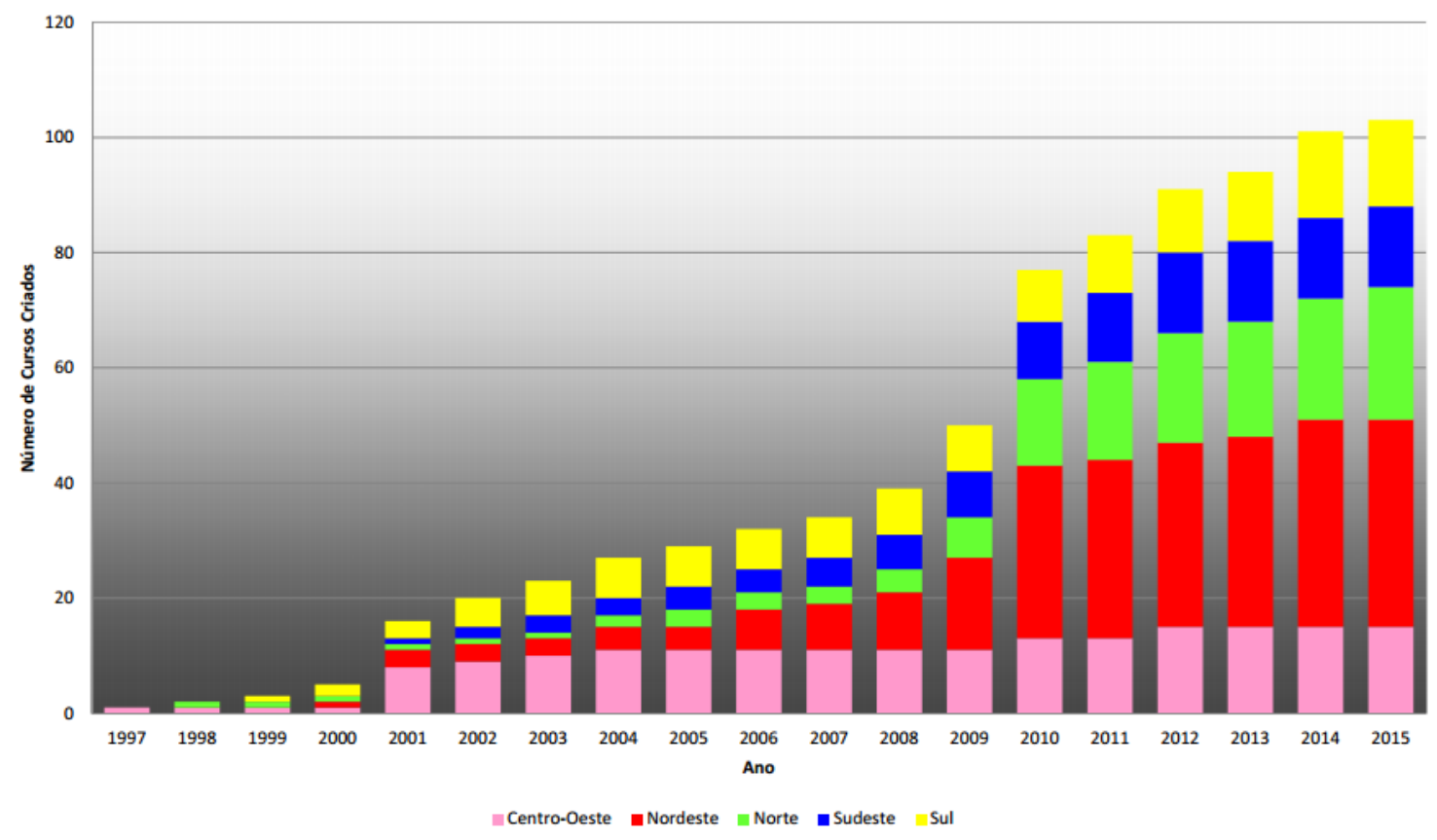

Figura 1: Evolução da oferta do curso (1997 - 2015)

\section{Desafios e Oportunidades}

Esta seção tem o objetivo de apontar e discutir os principais desafios e oportunidades observados por meio deste estudo. A seguir, cada desafio e oportunidade estarão organizados em subseções específicas.

\subsection{Articulação Entre Teoria e Prática na Perspectiva da Formação Docente}

A integração entre teoria e prática na formação docente por parte dos estudantes surge como um dos principais desafios observados pelos mesmos, que de modo geral deixam claro a dificuldade em conseguir associar o conhecimento teórico às suas atividades 
práticas durante o curso. Ao serem questionados sobre a qualidade da integração entre teoria e prática em seu curso (em uma escala de 1 a 5 representando respectivamente péssimo, ruim, regular, bom e ótimo), apenas 45,8\% dos estudantes, avaliaram integração entre teoria e prática de forma positiva (Figura 2). De modo geral, isto ocorre pelo fato das disciplinas não serem planejadas de forma conjunta, fazendo com que os estudantes dificilmente consigam colocar em prática os conhecimentos teóricos obtidos.

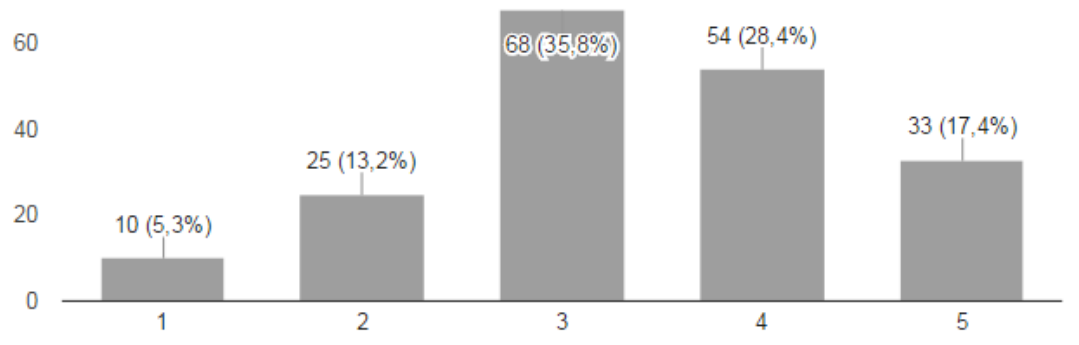

Figura 2. Avaliação de integração entre teoria prática

Tal situação pode ser considerada confusa pelo fato dos cursos de Licenciatura em geral possuírem disciplinas de Prática Pedagógica (onde os discentes podem participar de atividades que relacionam teoria e prática em cenários reais de ensino), bem como pelas Licenciaturas em Computação possuírem em sua grade curricular disciplinas obrigatórias de Estágio Supervisionado com base na Lei de Diretrizes e Bases da Educação Nacional, Lei 9394 (BRASIL, 1996), do Conselho Nacional de Educação - CNE. Ao mesmo tempo, o próprio CNE em suas atualizações, orienta que estas disciplinas devem ser usadas para que os estudantes possam colocar em prática (em ambientes reais como escolas e empresas) os conhecimentos teóricos obtidos nas demais disciplinas, com o objetivo de capacitação.

Assim, destaca-se como oportunidade a integração entre os conteúdos teóricos vivenciados no curso, objetivando a geração de espaços de imersão e desenvolvimento prático-didático. Diante do observado em estudos recentes, segundo Scaico et al. (2012) e Silva et al. (2015), uma abertura para execução destas atividades dá-se por meio das disciplinas de Prática Pedagógica e Estágios Supervisionados. Através delas, podem ocorrer ainda parcerias com empresas e/ou escolas públicas ou particulares que possam oferecer oportunidades de aplicação prática e de vivência do "chão de escola" ao Licenciando em Computação.

\subsection{Estruturação e Organização dos Estágios Supervisionados na perspectiva de Integração Entre os Assuntos de Computação e Educação}

Corroborando o desafio anterior da articulação entre teoria e prática, um dos principais desafios observados nesta pesquisa foi à desestruturação da disciplina de Estágio Supervisionado. De acordo com os resultados, os estágios não têm sido conduzidos de acordo com os objetivos traçados pelos Parâmetros Curriculares Nacionais - PCN. Esta disciplina, em geral, apresenta-se como mero espaço de apresentação teórica de conteúdos já vivenciados em outras disciplinas. Pode-se observar que ela foi destituída do seu objetivo primário que, de acordo com os PCN, é o de proporcionar aos 
estudantes a aplicação prática de conteúdos oriundos do curso, principalmente com relação à didática.

Para atacar este problema, acredita-se ser necessária maior integração das disciplinas de Estágio e de Prática Pedagógica às atividades de prática escolar. De acordo com recentes estudos de Silva Neto et al. (2015) e Silva et al. (2015), uma das principais formas de atingir este objetivo é por meio da realização de atividades de ensino, desenvolvimento ou extensão dentro dos estágios. Isto pode se dar por parcerias com instituições públicas e privadas que exerçam atividades relacionadas ao curso.

\subsection{Promoção e Abrangência das Oportunidades ao Egresso}

Diante dos resultados, um dos principais desafios revelados pela pesquisa foi à falta de oportunidades de atuação dos Licenciados em Computação. Ao serem indagados sobre qual o maior desafio enfrentado após a conclusão do curso (apenas para os estudantes que já haviam recebido o grau de licenciado), foram obtidas 54 respostas válidas, das quais 55,6\% afirmaram ser encontrar um cargo na área de Computação e/ou Informática na Educação o seu grande desafio (ver Figura 3). Quando questionados se já trabalharam na área, foram obtidas 95 respostas válidas, das quais mais da metade $(55,8 \%)$ nunca haviam trabalhado na área.

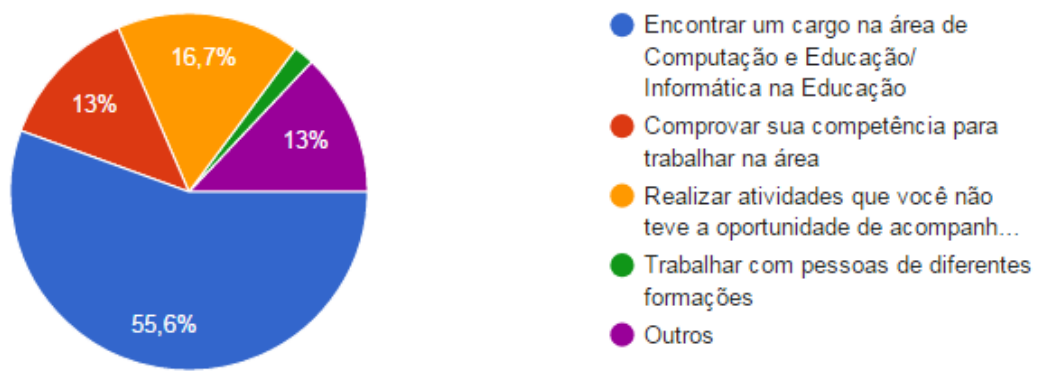

Figura 3. Principais desafios aos egressos

Este resultado surpreende, pois, há uma positiva perspectiva de crescimento das vagas para egressos do curso. Existe um número crescente de escolas técnicas federais e estaduais em diferentes regiões do país, sem contar que as escolas de Educação Básica também passam a incorporar professores de Computação no seu corpo docente. Portanto, os dados podem indicar desconhecimento do grupo pesquisado acerca das oportunidades de mercado para o Licenciado em Computação.

Frente a este desafio, torna-se necessária a promoção do curso de Licenciatura em Computação diante de entidades responsáveis pela contratação destes profissionais, bem como, da sociedade em geral. Segundo Queiroz et al. (2016) e Santos et al. (2016) ainda há pouco conhecimento do papel do Licenciado em Computação dentro das empresas e escolas - muitos até mesmo desconhecem a existência da profissão - sendo assim, necessário, tornar conhecido o curso e a importância dos profissionais formados pelo curso, na sociedade atual, cada vez mais cercada pelas novas tecnologias digitais. 
VI Congresso Brasileiro de Informática na Educação (CBIE 2017)

Anais do XXIII Workshop de Informática na Escola (WIE 2017)

\section{Limitações}

Apesar de se tratar de um estudo que propõe discutir desafios e oportunidades em um domínio de pesquisa, os dados foram obtidos mediante a realização de um estudo empírico. De acordo com Wohlin et al. (2012), isto pode levar a geração natural de limitações ou ameaças à sua validade. Sendo assim, esta seção descreve as precauções para replicações futuras deste estudo e outros aspectos que devem ser levados em conta para generalizar os resultados. Em geral, tentou-se minimizar muitas das limitações discutidas aqui. Para organizar esta seção, as limitações foram classificadas de acordo com as categorias descritas por Wohlin et al. (2012): interna, externa, construção e conclusão.

Interna: Como o estudo envolveu a participação ativa de seres humanos, tornase propenso a uma série de ameaças internas, como: ( $i$ ) história - é possível que o momento em que os estudantes responderam o questionário tenha ocorridos fatos que possam ter afetado os resultados; (ii) maturação - pelo fato de ser um questionário com grande volume de perguntas, é possível que eles estivessem entediados ou cansados ao responder à pesquisa; e (iii) viés positivo/negativo - é possível que os estudantes, devido a idade e fatores culturais, tenha uma visão pré-formada (positiva ou negativa sobre o objeto de estudo).

Externo: Diante da quantidade de cursos de Licenciatura em Computação no Brasil e, por conseguinte, do número de estudantes matriculados nesse curso, a quantidade de respostas válidas obtidas pode não ser significativo para que possamos ser capazes de generalizar os resultados do estudo para outros contextos mais amplos. Sendo assim, os aspectos deste estudo podem ser ampliados no intuito de obter-se resultados mais genéricos.

Construção: As ameaças desta categoria estão relacionadas principalmente ao seguinte aspecto: o estudo apresentado neste trabalho mede diferentes itens, de modo que alguns podem não ser medidos por meio de perguntas. Para minimizar essas limitações, selecionamos metodologias e instrumentos empiricamente validados e utilizados comumente em estudos científicos da comunidade de Informática na Educação.

Conclusão: As ameaças desta categoria estão relacionadas ao escopo do estudo. Neste sentido, é possível que os estudantes que responderam ao questionário, possam premeditadamente ter dado respostas que não sejam condizentes com sua realidade. Ao mesmo tempo, os profissionais que realizaram as análises dos dados podem, por ventura, ter deixado de considerar algum aspecto. No intuito de mitigar estas ameaças, todo processo de análises foi discutido com profissionais de considerável tempo de formação e atuação na área do estudo.

\section{Considerações Finais}

O curso de Licenciatura em Computação tem por objetivo formar professores para atuarem em todas as modalidades da Educação Básica na área de Computação. Desde 1997 - ano da primeira oferta do curso - o currículo vem sendo reformulado visando atender os aspectos legais e necessidade do ensino. No entanto, diante dos estudos 
VI Congresso Brasileiro de Informática na Educação (CBIE 2017)

Anais do XXIII Workshop de Informática na Escola (WIE 2017)

realizados nos últimos anos é possível perceber problemas relativos à identidade deste curso e adequação da prática pedagógica em sala de aula, tornando necessária identificação de desafios e oportunidades, com o objetivo de planejar os próximos anos de formação.

Neste sentido, este estudo realizou uma pesquisa com estudantes em formação e recém-formados em cursos de Licenciatura em Computação no Brasil. Foram obtidas 190 respostas válidas de estudantes de 14 diferentes instituições Brasileiras. Os principais resultados basearam-se em três indicadores: (i) articulação entre teoria e prática na perspectiva da formação docente, (ii) estruturação e organização dos estágios supervisionados na perspectiva de integração entre os assuntos de Computação e educação e (iii) promoção e abrangência das oportunidades ao egresso.

Diante do exposto, propõem-se como trabalhos futuros a identificação de novos desafios na perspectiva do professor (professor de Licenciatura em Computação) que possam corroborar com os descritores apresentados neste texto, bem como aprofundar as análises apresentadas ao longo do artigo, por exemplo, por meio da análise das respostas dadas a outras perguntas feitas no questionário e não abordadas neste artigo, por exemplo, compreender e discutir as respostas textuais livres deixadas pelos estudantes que responderam o questionário a respeito dos desafios percebidos durante $o$ curso.

\section{Referências}

Brasil. Constituição da República Federativa do Brasil (1988) Disponível em $<<$ http://www.senado.gov.br/legislacao/const/con1988/con1988_05.10.1988/con198 8.pdf $>$. Acesso em: 07 de Maio de 2017.

Brasil. Ministério da Educação - MEC. (1996) "Lei de Diretrizes e Bases da Educação Nacional - LDB”. http://www.planalto.gov.br/ccivil_03/leis/L9394.htm, Maio.

Brasil. Ministério da Educação - MEC. "Planejando a próxima década: conhecendo as 20 metas do Plano Nacional de Educação". (2014) http://pne.mec.gov.br/images/pdf/pne_conhecendo_20_metas.pdf, Maio.

Castro, C. S., \& de Oliveira Vilarim, G. (2013). Licenciatura em Computação no cenário nacional: embates, institucionalização e o nascimento de um novo curso. Revista Espaço Acadêmico, 13(148), 18-25.

Cruz, M. K., Becker, F., \& Hinterholz, L. (2016). Carga Horária Prática na Formação de Professores de Computação e Informática Educativa. In Anais do Workshop de Informática na Escola (Vol. 22, No. 1, p. 698).

Matos, E., \& Silva, G. F. B. (2012). Currículo de licenciatura em Computação: uma reflexão sobre perfil de formação à luz dos referenciais curriculares da SBC. In XXXII Congresso da Sociedade Brasileira de Computação - XX Workshop de Educação em Computação. 
VI Congresso Brasileiro de Informática na Educação (CBIE 2017)

Anais do XXIII Workshop de Informática na Escola (WIE 2017)

Nunes, D. J. (2011). Ciência da Computação na Educação Básica, Disponível em: <http://www.adufrgs.org.br/artigos/ciencia-da-Computação-na-educacao-basica/>. Acesso em 20 de Maio de 2017.

Nunes, D. J. (2015). Educação Superior em Computação, Estatísticas 2015. Sociedade Brasileira de Computação-SBC. Disponível em:< http://www.sbc.org.br/documentos-da-sbc/summary/133-estatisticas/1074-educacaosuperior-em-Computação-estatisticas-2015>. Acesso em, 06 de Maio de 2017.

Papert, S., Valente, J. A., \& Bitelman, B. (1980). Logo: computadores e educação. Brasiliense.

Prietch, S. S., \& Pazeto, T. A. (2010). Mapeamento de cursos de licenciatura em Computação seguido de proposta de padronização de matriz curricular. In XVIII Workshop de Educação em Computação (WEI 2010), Anais do XXX Congresso da Sociedade Brasileira de Computação-CSBC (pp. 921-930).

Queiroz, P., Santos, H., \& Rodrigues, A. (2016, November). Relato de Experiência no PIBID: Projeto interdisciplinar envolvendo Licenciandos em Computação e Pedagogia no Ensino Fundamental. In Anais do Workshop de Informática na Escola (Vol. 22, No. 1, p. 963).

Referenciais de Formação em Computação, Cap. V "Referenciais de Formação em Computação: Licenciatura em Computação". (2017) http://www.sbc.org.br/noticias/10-slideshow-noticias/1979-consulta-publica-sobreos-referenciais-de-formacao-em-Computação-da-sbc, Maio.

Santos, N., Pontes, D. N., Santos, L., \& Hounsell, J. (2016). Softwares educacionais: O papel do licenciado em Computação na escola. In Anais dos Workshops do Congresso Brasileiro de Informática na Educação (Vol. 5, No. 1, p. 363).

Scaico, P. D., Henrique, M. S., Cunha, F. O. M., \& de Alencar, Y. M. (2012). Um relato de experiências de estagiários da licenciatura em Computação com o ensino de Computação para crianças. RENOTE, 10(3).

Silva, S.F., Ferreira, A., Souza, A.A., Galdino, E., Oliveira, M.L.S., Neto, S. e Oliveira, W. (2015) "Relato de Experiência de Ensino de Computação no Ensino Fundamental em Estágio Supervisionado da Universidade de Pernambuco no Campus Garanhuns", In: 23ํ Workshop sobre Educação em Computação, p. 1-10.

Silva Neto, S. R., Santos, H. R. M., \& Santos, W. O. (2015) "ABILSEN: Uma Abordagem para Inclusão do Licenciado em Computação no Ensino Básico". In: $23^{\circ}$ Workshop sobre Educação em Computação, p. 1-10.

Wohlin, C., Runeson, P., Höst, M., Ohlsson, M. C., Regnell, B., \& Wesslén, A. (2012). Experimentation in software engineering. Springer Science \& Business Media. 